\title{
STUDY OF ANATOMICAL VARIATION IN POSTERIOR CEREBRAL ARTERY \& POSTERIOR COMMUNICATING ARTERY IN HUMAN CADEVER
}

\section{Dr. Smita B. Shinde*}

\section{Dr. G. A. Shroff}

Assistant Professor in Anatomy Department of Anatomy MGM's Medical College and Hospital Aurangabad (M.S.) India * Corresponding Author

Professor in Anatomy Department of Anatomy MGM's Medical College and Hospital Aurangabad (M.S.) India

Associate professor in Anatomy Department of Anatomy MGM's Medical College and Hospital Aurangabad (M.S.) India

Dr. savita kadam

ABSTRACT Study sample 50 well formalin preserved brain from cadavers in dissection hall of MGMs Medical College in year of 2018-19. Length is measured by thread and diameter measured by venire caliper. The origin and course of posterior cerebral artery \& posterior communicating artery in all brains observed.

In present study the length of posterior cerebral artery is $1.1 \mathrm{~cm} \&$ diameter is $2.1 \mathrm{~mm}$ so as compared to previous studies diameter is same but length is more.

KEYWORDS : posterior cerebral artery, posterior communicating artery, Human Cadavers

\section{INTRODUCTION:}

The brain is supplied by two internal carotid and two vertebral arteries. The branches of these arteries anastomosis on the inferior surface of the brain to form the circular arteriosus(1). The vessels contributing to the formation of circulus arteriosus are the anterior, middle and posterior cerebral arteries. Posterior cerebral artery is the terminal branch of basilar artery curves laterally backwards. Posterior communicating artery joins the posterior cerebral artery to the internal carotid $\operatorname{artery}(2)$.

Cerebral artery occlusion leads to infarction in the brain tissue. The occlusion is caused by stenosis, embolism or rupture of the arteries. Though many workers have reported abnormalities in the diameters of the vessels forming the Circle of Willis, the normal dimensions of these vessels have not been reported. The vessels have been described as narrow, thread like, string like but the actual diameter has rarely been measured. Most of the anatomical variations reported are related posterior cerebal and the posterior communicating arteries. However there are very few case reports regarding the variations encountered in the anterior cerebral arteries(3).

Hence the present study was undertaken to study the origin, length and diameter of posterior cerebral \& posterior communicating arteries.

\section{MATERIALS AND METHODS:}

Study sample: Fifty well formalin preserved brains from cadavers in dissection hall of Mahatma Gandhi Missions Medical College, Aurangabad.

\section{Instruments}

The instrumentation required were scalpel, forceps, scissors, measuring scale, brush, cotton, gloves, oil paint and vernier caliper.

\section{METHOD:}

The cadavers were placed in supine position. A pencil mark was made on the skull by encircling it horizontally. By making saw cut along the line skull cap was removed.

To remove the brain in one piece, the falx cerebri from the crista galli was detached. Falx pulled posteriorly. A block of wood placed under the shoulder to allow the head to fall back. This allows the frontal lobe to move out of anterior cranial fossa, the optic nerve, internal carotid, and infundibulum were cut. The posterior part of hemisphere was raised with fingers, pressing the Pons further posteriorly and knife was passed into the vertebral canal in front of medulla oblongata cutting firmly from side to side. The brain was withdrawn from cranial cavity(4).

Fifty brains were removed from cranial cavity using the above procedure. The posterior cerebral \& posterior communicating arteries were observed.

posterior cerebral artery studied in both sides from their origin .The origin course diameter, length and number is observed \& posterior communicating artery is also observed.

\section{RESULTS:}

The origin and course of posterior cerebral artery in all brains were same.

In all the brains, the artery was found to be single. Hyperplasia was seen in 11 brains on the right side and 10 brains on the left side. (Table-1,3) (Photographl)

\section{Posterior Communicating Artery}

In all specimen the artery was single. In 21 brains it was narrow or string like. Absence of the artery was not observed.(Table-2) (photograph-2)

\section{DISCUSSION :}

Thomas Willis was the first scientist to describe the circulus arteriosus In 1962. He was born on 27 January great Bedwyn in Wiltshir England, the son of a farmer who lost his life at the blege of Oxford during civil war(5).

Variation in these arteries which is associated with attraction of blood flow to the brain, enhances the problem in vascular diseases of brain(6).

There are also different methods of studying these arteries, we can study by magnetic resonance imaging (MRI) or angiography.

In the present study origin \& course posterior cerebral artery were studied and compared with the previous studies.

The diameter of the right posterior cerebral artery mentioned by Kamath S. in(1981) with dissection method was $2.1 \mathrm{~mm}$. In the present study it is $2.1 \mathrm{~mm}(1)$.

The diameter of the left posterior cerebral artery mentioned by 
Kamath S. in (1981) with dissection method was 2.2mm.In present study it is $2.2 \mathrm{~mm}(1)$

The diameters of both posterior cerebral arteries mentioned by Saeki $\mathrm{N}$ et al in (1977) in autopsy specimen were $2.6 \mathrm{~mm}$ (7).

The length of right and left posterior cerebral artery mention by Kamath $S$ in (1981) with dissection method were $0.68 \mathrm{~cm}$ and $0.69 \mathrm{~cm}$ respectively. In the present study the length of both side is $1.1 \mathrm{~cm}$ (1). (Table-3, Graph 1 and 2).

\section{Posterior Communicating Ärtery}

Hypoplasia of post communicating arteries noted by Puchades Orts el al in (1975) with dissection method was $51.6 \%(8)$.

In the presented study hypoplasia in the posterior communicating artery is $40 \%$.

The percentage of absence of posterior communicating arteries noted by Punchades Orts et al in (1975) with dissection method was $2.4 \%$. Reddy $\mathrm{RD}$ et al in (1972) with dissection method was $16 \%$. In the present study the absence of posterior communicating artery is not found $(1,9)$. (Table-2)

\section{CONCLUSIONS:}

The diameter of the posterior cerebral artery in the present study $2.1 \mathrm{~mm}$ which coinciding with Kamath $\mathrm{S}$ which was $2.1 \mathrm{~mm}$.The length of the posterior cerebral artery according to Kamath S. $0.68 \mathrm{~cm}$.while in our findings it was $1.1 \mathrm{~cm} .(1)$ - (graph-1,2)

In our study there was not much deviation from the findings of other scientists in the diameter and length of posterior cerebral arteries.

The variations in the posterior communicating arteries showed significant variation in number, shape and size which was $40 \%$ as compared to Puchades-Orts et al who found $51.6 \%$ (8).

Table - 1 Variations of the Posterior Cerebral Artery

\begin{tabular}{|l|c|c|c|}
\hline Observation & Rt. & Lt. & Total \\
\hline & 50 & 50 & 100 \\
\hline Hyperplasia & 11 & 10 & - \\
\hline Hypoplasia & - & - & - \\
\hline Duplication & - & - & - \\
\hline
\end{tabular}

Table No-2 Variations of Posterior Communicating Artery

\begin{tabular}{|l|c|c|c|}
\hline \multicolumn{1}{|c|}{ Observations } & Rt. & Lt. & Total \\
\hline Posterior Communicating & 50 & 50 & 100 \\
\hline Narrow or string like (Hypoplasia) & 11 & 10 & - \\
\hline Dilated (Hyperplasia) & - & - & - \\
\hline Absent & - & - & - \\
\hline Normal & 39 & 40 & 79 \\
\hline
\end{tabular}

Table - 3 Descriptive Statistics - Posterior

\begin{tabular}{|c|c|c|c|c|c|c|}
\hline Posterior & N & $\begin{array}{l}\text { Mini } \\
\text { mum }\end{array}$ & $\begin{array}{l}\text { Maxi } \\
\text { mum }\end{array}$ & Mean & $\begin{array}{c}\text { Std. } \\
\text { Deviation }\end{array}$ & CV\% \\
\hline Posterior Right - Length & 50 & 1.00 & 1.20 & 1.0560 & $6.115 \mathrm{E}-02$ & 5.79 \\
\hline Posterior Left - Length & 50 & 1.00 & 1.20 & 1.0560 & $6.749 \mathrm{E}-02$ & 6.39 \\
\hline $\begin{array}{c}\text { Posterior Right - } \\
\text { Diameter }\end{array}$ & 50 & 1.50 & 3.00 & 2.1340 & .4178 & 19.58 \\
\hline Posterior Left - Diameter & 50 & 1.20 & 3.00 & 2.1760 & .4488 & 20.63 \\
\hline
\end{tabular}

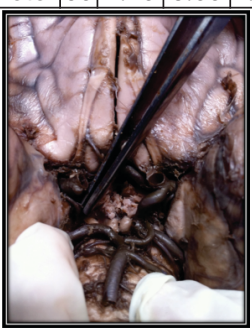

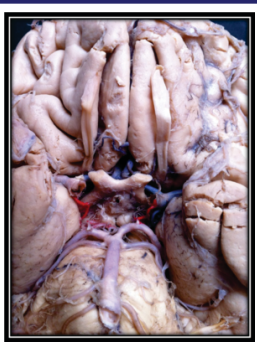

Photograph showing diameter of posterior communicating artery

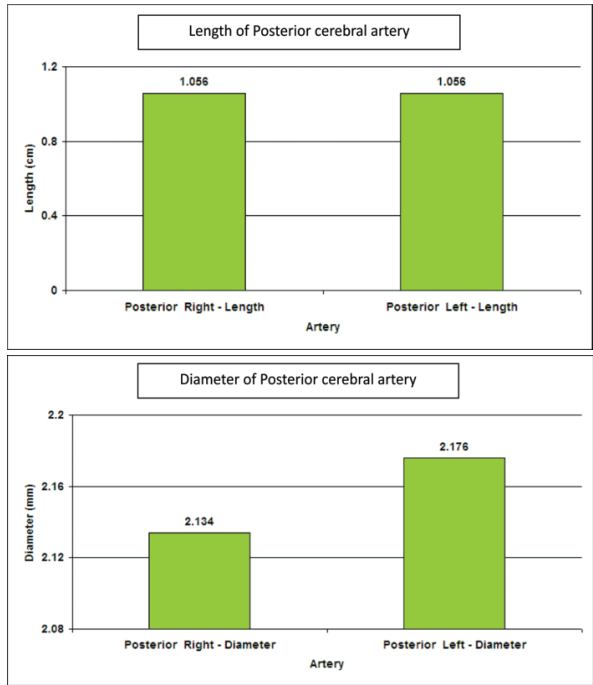

\section{REFERENCES :}

1. Kamath S. Observations on the length and diameter of vessels forming the circle of Willis J Anat. 1980: 133:419-23.

2. Snell RS. Clinical Neuroanatomy. Blood Supply of Brain, 6th edition. Lippincott Williams \& Wilkins, Philadelphia 2006 Pg. 469-476.

3. Koyama S. Giant aneurysum of pericallosal artery causing subdural hematoma- case report. Neural Med Chirr 2000; 40:268-71.

4. Ross M H ,Pawlina W.Histology a test and atlas with correlated cell and molecular biology.5thEdition.Philadelphia; Lippincott Williams \& Wilkins, 2006;377.

5. Hassan's, Peter KK, Julius AO; Varient Anatomy of anterior cerebral artery in adult brain. African Journal of N eurological sciences 2002; vol 27, no.1.

6. Hina siddiqi, Mohammad Tahir AL.Variation in cerebral arterial circle of willis in adult Pakistani population. Journal of college of physicians \& surgeons Pakistan 2013;vol 23,no.9:615-619

7. Saieki N, Rhoton AL. Microsurgical anatomy of upper basilar artery and posterior-circle of Willis, J Neuroanat. 1977; 46:563-78.

8. Puchades-Orts, Nombela GM, Ortuno-G; Variations in the form of circlr of willis: some anatomical \& embryological considerations. Anatomical record 1975;185:119-124.

9. Roman GJ Cunningham's Manual of Practical Anatomy,the blood vessels of the brain.15th edition vol.3New Yark.ELBS Oxford University press.1986.215222. 